\title{
Eradication of glioblastoma by immuno-virotherapy with a retargeted oncolytic HSV in a preclinical model
}

\author{
Francesco Alessandrini ${ }^{1} \cdot$ Laura Menotti $^{2} \cdot$ Elisa Avitabile $^{2} \cdot$ Irene Appolloni $^{1} \cdot$ Davide Ceresa $^{1} \cdot$ Daniela Marubbi $^{1,3}$. \\ Gabriella Campadelli-Fiume ${ }^{4}$.Paolo Ma latesta ${ }^{1,3}$
}

\begin{abstract}
Oncolytic herpes simplex viruses are proving to be effective in clinical trials against a number of cancers. Here, R-115, an oncolytic herpes simplex virus retargeted to human erbB-2, fully virulent in its target cells, and armed with murine interleukin- 12 was evaluated in a murine model of glioblastoma. We show that a single R-115 injection in established tumors resulted, in about $30 \%$ of animals, in the complete eradication of the tumor, otherwise invariably lethal. The treatment also induced a significant improvement in the overall median survival time of mice and a resistance to recurrence from the same neoplasia. Such a high degree of protection was unprecedented; it was not observed before following treatments with the

commonly used, mutated/attenuated oncolytic viruses. This is the first study providing the evidence of benefits offered by a fully virulent, retargeted, and armed herpes simplex virus in the treatment of glioblastoma and paves the way for clinical translation.
\end{abstract}

\section{Introduction}

Herpes simplex virus 1 (HSV-1) is among the most studied oncolytic viruses for treating several types of cancers. HSV-1 has relevant characteristics as therapeutic agent: it has a large genome that can accommodate exogenous genes, does not integrate into the host genome, and is not oncogenic [ [ 15$]$. Moreover, anti-HSV-1 drugs are available to block virus replication in case of uncontrolled infection while the presence of pre-existing antibodies against the virus does not

Paolo Malatesta paolo.mal atesta@unige.it

1 Department of Experimental Medicine, University of Genoa, Genoa, Italy

2 Department of Pharmacy and Biotechnology, University of Bologna, Bologna, Italy

3 Ospedale Policlinico San Martino IRCCS per l'Oncologia, Genoa, Italy

4 Department of Experimental, Diagnostic and Specialty Medicine, University of Bologna, Bologna, Italy seem to impair its infectivity [6,7]. Oncolytic HSVs (oHSVs) are emerging as one of the efficient therapies to fight malignant neoplasms lacking effective therapeutic altematives [8]. Clinical trials are ongoing to test the safety and the efficacy of oHSVs against colorectal, breast, and non-resectable pancreatic cancers [9 11 ]. Recently, T-VEC, an oHSV with tumor-selective replication that expresses granulocyte monocyte colony stimulating factor, has been approved as therapy for nonresectable metastatic melanoma $[12,13]$.

A noteworthy potential target for oHSV therapy is glioblastoma [14, 15], the most aggressive form of brain tumor and one of the most lethal types of human cancer, classified by WHO as grade IV glioma [16]. The life expectancy of glioblastoma patients has not substantially changed in the past 50 years. The median survival time of patients treated with the standard of care protocol is about 14 months; only $10 \%$ of them survive for more than 5 years from diagnosis [17]. The challenging properties of glioblastoma are its tendency to infiltrate the healthy brain parenchyma and its high radio- and chemo-resistance. As a consequence, the incidence of recurrence after surgical resection is high. In this picture, oncolytic viroimmunotherapy may represent a breakthrough since viral spread could potentially hit disseminating cells. Oncolytic viruses have the advantage that they can disseminate to adjacent cancer cells and kill them. In addition, they stimulate the immune system so as to break the tolerance against the 
tumor. Although for a long time the central nervous system (CNS) has been considered a privileged site of immunity, this paradigm is currently disputed and there is growing evidence that activated $\mathrm{T}$ cells are able to recognize their targets even when they are located within the CNS parenchyma $[18,19]$. oHSVs offer the possibility to be armed with immunostimulatory molecules. In recent years, evidence that the expression of mIL-12 increases the effectiveness of oncolytic viruses by activating the immune response has been provided, thus potentiating the clearance of cancer cells through an immunotherapeutic effect [20 22]. Preclinical trials were conducted with oHSVs armed with mIL-12 for ovarian cancer [23], breast cancer brain metastases [24], and also glioblastoma [25]. An HSV armed with IL-12 is currently under the phase 1 clinical trial [26].

The above studies exploited HSV recombinants attenuated to varying degrees by genetic manipulation, in order to achieve cancer-specific replication. In a strikingly different approach, we recently assayed the safety and the efficacy of a replication-competent tropism-retargeted oHSV, fully virulent in its target cells, named R-LM113. R-LM113 is retargeted at the human receptor tyrosineprotein kinase erbB-2 (hHER2, human epidermal growth factor receptor 2), a receptor expressed in a number of tumors. hHER2 is a clinically relevant target for high-grade gliomas (HGGs) since it is expressed in a large fraction of these tumors, quantified between 15 and $80 \%$ depending on the technology employed for detection [27 29]. Malignancy of gliomas positively correlates with hHER2 expression $[30,31]$, which is particularly high in the CD133-positive, stem cell-like, glioblastoma cells [32]. Furthermore, hHER2 expression is virtually absent in healthy brain parenchyma, confirming its suitability and specificity as target [33]. In a murine model developed in our laboratory, R-LM113 counteracted HGG [34, 35]. Of note, the retargeted oHSVs are intrinsically safer than the attenuated ones, replicate to higher yields, and can be readily engineered so as to target different cancer-specific receptors [36].

Here, for the first time, we report on the efficacy of a fully virulent, retargeted oHSV-1, armed with mIL-12 (R-115 [37]) in counteracting glioma. The effects of treatment were tested against established orthotopic HGGs in a syngeneic glioma model in the BALB/c mouse strain.

\section{Results}

\section{Mouse PDGF-driven glioma cells show hallmarks of human glioblastoma and are poorly immunogenic}

To study the effects of the mIL-12-armed hHER2-retargeted oHSV (R-115) on HGGs, we took advantage of a model of HGG based on the transduction of platelet-derived growth
factor-B (PDGF-B) in neural progenitor cells derived from BALB/c mice, a mouse strain sensitive to HSV infection [35]. The HGG model was generated by transplanting in adult mouse brains murine neural progenitor cells explanted at embryonic day 14 (E14) and transduced with a PDGF-B overexpressing retroviral vector as described elsewhere [34]. The generated HGGs, hereinafter referred to as $\mathrm{mHGG}^{\text {pdgf }}$, express markers typical of oligodendroglial progenitor cells (OPCs) and exhibit histological features typical of human HGGs, as previously described [35]. Here, mHGG $^{\text {pdgf }}$ cells were further characterized by RNA sequencing carried on three independent tumor specimens (raw data are available on GEO Dataset. Accession number GSE109614). The analysis showed that $\mathrm{mHGG}^{\text {pdgf }}$ cells express OPC markers such as Olig2, PDGFR-alpha, and NG2 as well as stem cell markers, including Sox2, Stat3, and Nestin (Fig. 1a). mHGG ${ }^{\text {pdgf }}$ cells showed very low levels of mRNAs for immune system co-stimulatory molecules CD40 and CD80, and the IL-12 and IL15 cytokines. Low levels of expression were also observed for the co-stimulatory molecule CD86. On the contrary, the immunosuppressive gene CD73 [38] was highly expressed. This pattern is consistent with $\mathrm{mHGG}^{\text {pdgf }}$ being poorly immunogenic, as typically seen in human glioblastomas.

Primary $\mathrm{mHGG}^{\text {pdgf }}$ were microdissected, cultured, and engineered to express hHER2 receptor. hHER2-transduced cells (hereinafter referred to as $\mathrm{mHGG}^{\text {pdgf }}-\mathrm{hHER} 2$ ) maintained the tumorigenic potential exhibited by the parental mHGG $^{\text {pdgf }}$ cells, and were able to consistently generate tumor masses after intracranic transplantation of $2 \times 10^{4}$ cells in adult immunocompetent mice leading them invariably to death (Supplementary figure 1).

\section{R-115 efficiently infects hHER2-positive glioma cells in vitro, and mediates $\mathrm{mIL}-12$ secretion}

To assess if $\mathrm{mHGG}^{\text {pdgf }}$-hHER2 are susceptible to R-115 infection in vitro and to compare R-115 with R-LM113, whose efficiency was reported earlier [35], we infected $\mathrm{mHGG}^{\text {pdgf }}$-hHER2 cells with R-115 or R-LM113 at the multiplicity of infection (MOI) of 0.5 plaque-forming units (PFU) per cell, as titrated in SK-OV-3 cells. Viral infection was scored as expression of the EGFP reporter gene inserted in the virus genome. After $30 \mathrm{~h}$, we observed an equivalent percentage of infected cells in the R-115and R-LM113-infected cultures (Fig. 1b, c). To ensure that R-115 exhibited the specific hHER2 tropism typical of R-LM113, the control hHER2-negative $\mathrm{mHGG}^{\text {pdgf }}$ monolayers were inoculated with R-115. No EGFP-positiveinfected cells were detected up to $96 \mathrm{~h}$ after exposure to the virus (Fig. 1d). mHGG $^{\text {pdgf }}$-hHER2-expressing cells infected with R-115 and monitored for $72 \mathrm{~h}$ after infection produced and secreted mIL-12 in the medium, in a MOI-dependent 
A

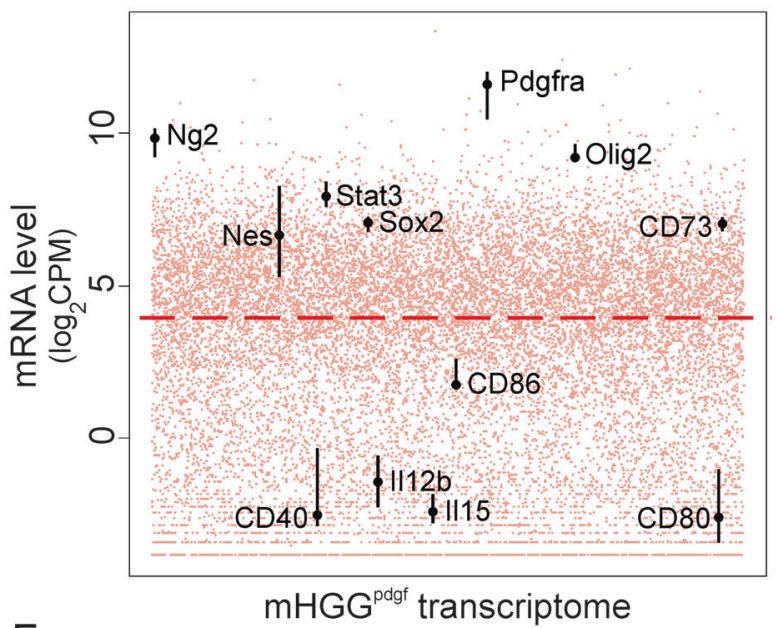

E

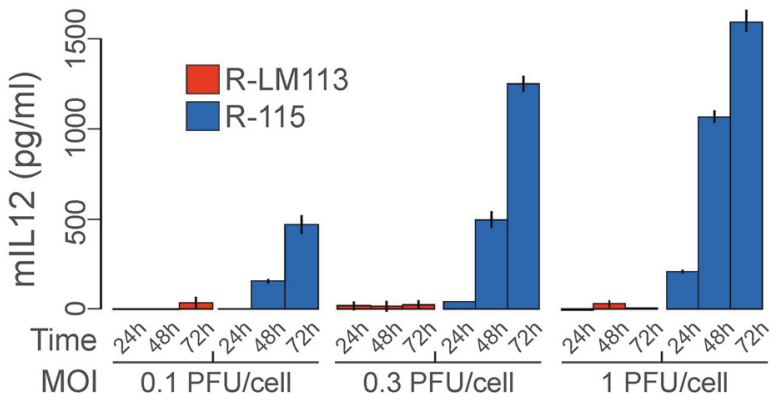

B
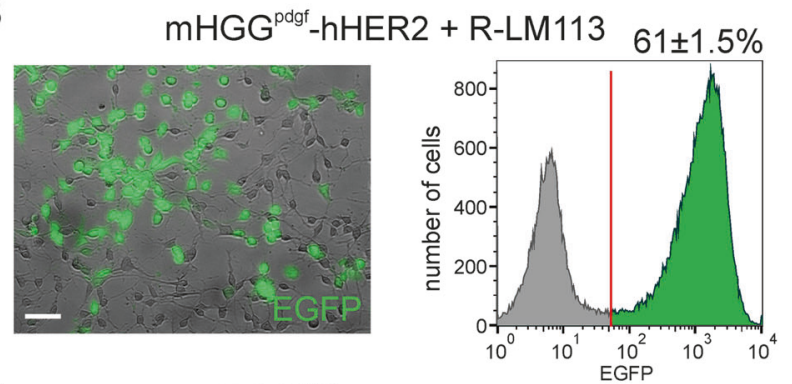

C

$\mathrm{mHGG}^{\text {pdgf }}-$ hHER2 + R-115

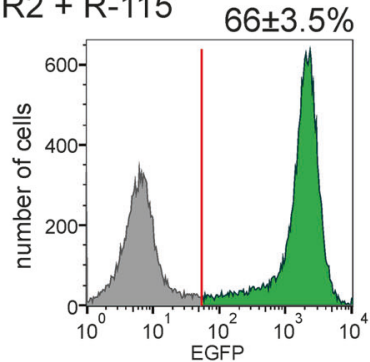

D
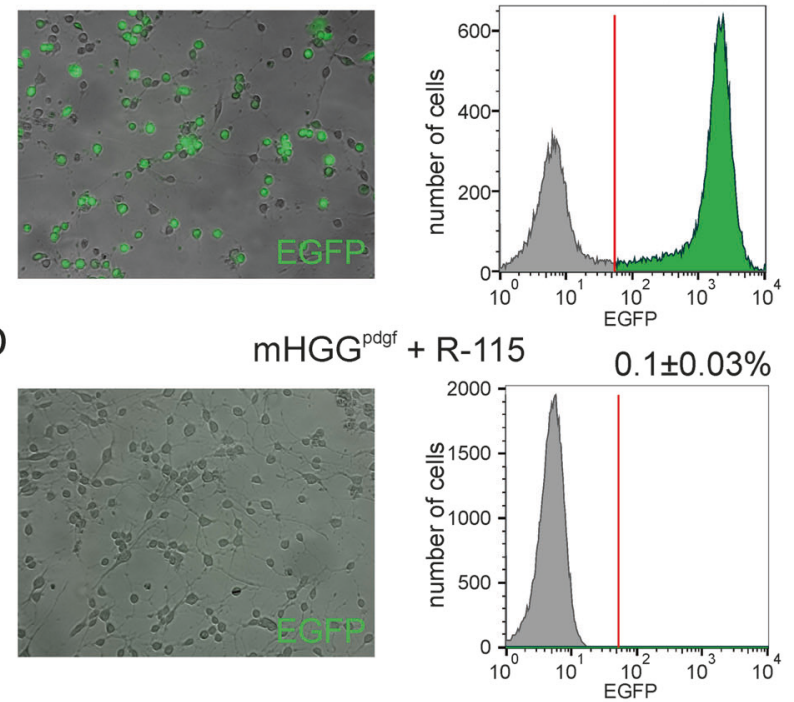

F

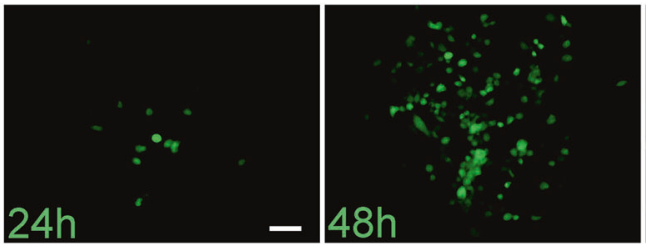

Fig. 1 a Expression levels of the whole transcriptome of $\mathrm{mHGG}^{\mathrm{pdgf}}$ cells as determined by RNA seq analysis from three independent tumors. Genes of interest are highlighted and the level of their expression is represented as a bar summarizing the results from the three samples. Black dots represent the median. Dashed red line represents the overall median expression level across the whole tran scriptome. The arrangement of the genes along the $x$ axis is rando mized. b d Infection of $\mathrm{mHGG}^{\text {pdgf }}$ hHER2 cells with $0.5 \mathrm{PFU} /$ cell of R LM113 (b) or R 115 (c), or of the parental $\mathrm{mHGG}^{\text {pdgf }}$ cells with 0.5

fashion (Fig. 1e). In addition, we monitored the time course of R-115 infection in $\mathrm{mHGG}^{\text {pdgf }}$-hHER2 cell monolayers, after infection at low MOI (0.01 PFU/cell, as titrated in SKOV-3 cells). The collected images showed that R-115 progeny was able to efficiently spread in culture (Fig. 1f).

The ability of R-115 to infect hHER2-expressing cells is not limited to the engineered murine models. We tested R115 on 11 independent glioma-initiating cell (hGic) cultures obtained from glioblastoma patients [39], code-named hGic-G6，-G7，-G10，-G14，-G17，-G19，-G21，-G24, $-\mathrm{G} 33,-\mathrm{G} 37$, and -G39. We found that they expressed
PFU/cell of R 115 (d). Pictures were taken $30 \mathrm{~h}$ after infection. His tograms show the corresponding cytofluorimetric quantifications of the cells expressing the EGFP reporter expressed by the viral genome. e ELISA quantification of mIL 12 concentration in supernatants of $\mathrm{mHGG}^{\text {pdgf }}$ hHER2 cells infected with R LM113 (red bars) or R 115 (blue bars) at the indicated MOI and times after infection. Error bars indicate standard deviation. f Time course of $\mathrm{R} 115$ infection in $\mathrm{mHGG}^{\text {pdgf }}$ hHER2 monolayers (input MOI 0.01 PFU/cell). Scale bars: $50 \mu \mathrm{m}$

hHER2 receptor at different levels and were efficiently infected by R-115, with a higher extent in cultures displaying higher HER2 expression levels. Glioma-initiating cell cultures (hGic-G14 and -G33) that did not express hHER-2 were not infected by R-115 (Fig. 2a). In order to verify that oHSV infection leads to cell death, we performed flow cytometry-based analysis of three of hGic cultures (Fig. 2b and data not shown) by evaluating apoptosis and necrosis markers. Compared to the control, we observed the appearance of high percentages of early apoptotic (Annexin V-positive) and necroptotic/late apoptotic (Annexin V-and 
A
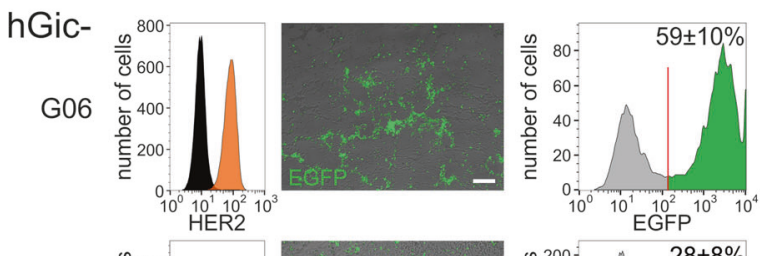

G07
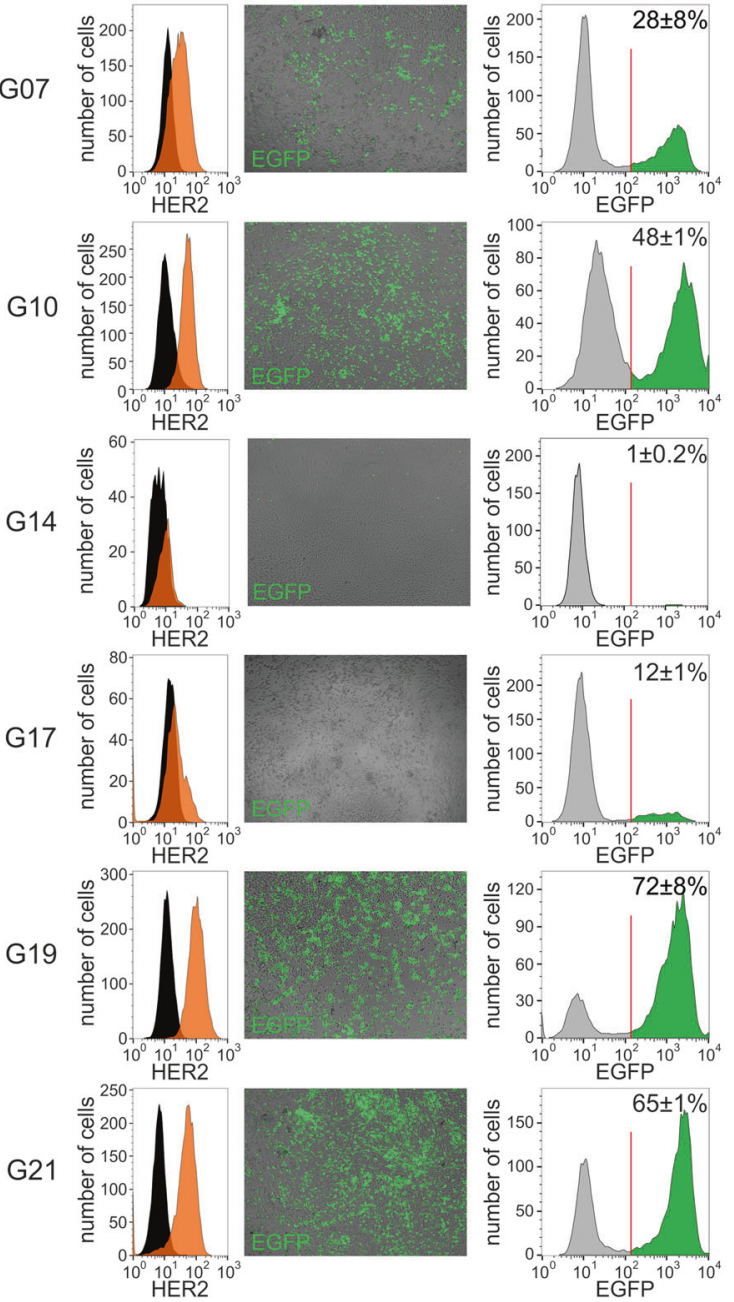

Fig. 2 a Cytofluorimetric quantification of hHER2 expression (orange peaks; negative control in black), of the indicated hGic cultures, micrograph of the corresponding cultures $40 \mathrm{~h}$ after infection with 5 PFU/cell of R 115 (Scale bar: $50 \mu \mathrm{m}$ ) and cytofluorimetric quantifi cations of the percentage of infected cells based on EGFP reporter

Necrosis Detection Reagent-positive) cells after infection with R-115 (Fig. 2b). This is the typical cell death induced by HSV infection [40].

\section{In vivo inhibition of tumor growth by R-115 in immunocompetent mice and induction of cancer- specific immune memory}

The R-115 efficacy in counteracting gliomas was analyzed as ability to inhibit the progressive growth of established
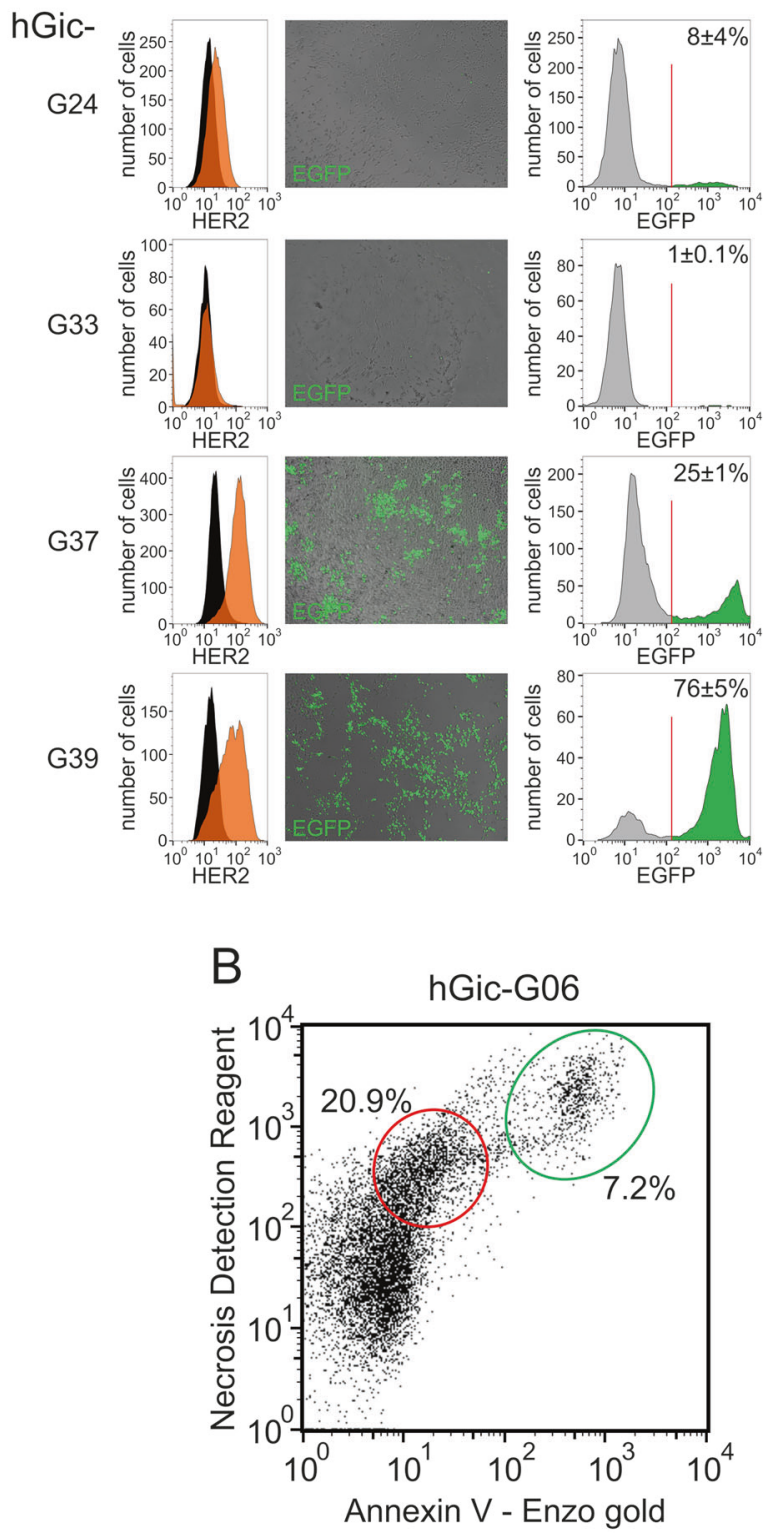

expressed by R 115 (gray and green peaks). b Cytofluorimetric ana lysis of early apoptotic (red circle) and necroptotic/late apoptotic cells (green circle) of hGic G06 culture $120 \mathrm{~h}$ after infection with 5 PFU/cell of R 115

mHGG $^{\text {pdgf }}$-hHER2 tumors in vivo. Mice bearing tumors induced by orthotopic transplantation of $\mathrm{mHGG}^{\text {pdgf }}$-hHER2 cells in the left cranial hemisphere were randomized and treated by intracranic injection of $2 \times 10^{6}$ PFU of R-115 (R-115 low dose arm), or the same amount of R-LM113 (R-LM113 arm), 21 days after tumor implantation. The control group was injected with an equivalent volume of gamma-irradiated R-LM113 (control arm). In an additional arm, R-115 was injected at a higher concentration $\left(10^{8}\right.$ PFU; R-115 high-dose arm). The animals that did not 
survive intracranial injection procedure and died within 3 days from virus injection were excluded from the experiment $(n=1)$. In total, we analyzed 14 mice in the R-115 low-dose arm, 8 in the R-115 high-dose arm, 12 mice in the R-LM113 arm and 10 mice in the control arm. Analysis of survival curves revealed no difference between the R-115 low- and high-dose arms (log rank-test power $1 \quad \beta \geq 0.8$ for $H R \leq 0.33$, Supplementary figure 2) and therefore the two arms were considered hereafter as a single one (R-115 arm) including 22 mice (Fig. 3a).

The median survival time of animals in the control arm was 13 days from the treatment, while that of mice belonging to the R-LM113 and R-115 arms were respectively 33 and 35 days. Survival time in both treatment arms (R-LM113 and R-115) was significantly different from that in the control arm (log rank-test $p<0.0001$; Fig. 3a). No statistically significant difference in term of median survival time was detected between the two different oHSVs (log rank-test power $1 \quad \beta \geq 0.8$ for $\mathrm{HR} \leq 0.4$ ). However, a dramatic difference between the R-LM113 and R-115 arms was evident in terms of long survivors. While in the R-LM113 arm all mice died within 48 days from treatment, $27 \%$ of mice treated with R-115 ( $n=6,4$ belonging to lowdose arm and 2 to high-dose arm) were still alive 100 days after the virus treatment. Two long survivors were sacrificed and resulted tumor-free (Fig. 3b). Other two were implanted with additional $2 \times 10^{4} \mathrm{mHGG}^{\text {pdgf }}$-hHER2 cells in the contralateral hemisphere relative to the first injection and received no further virus treatment. In parallel, the same amount of cells was injected into the right hemisphere of four control mice. The animals belonging to the control set died within 26 days after transplantation. Conversely, the two R-115-treated mice were still alive 220 days after the transplant in the contralateral hemisphere (Fig. 3c). The mice were additionally orthotopically transplanted, with $2 \times$ $10^{4}$ cells from the parental $\mathrm{mHGG}^{\text {pdgf }}$ culture, lacking hHER2. Even in this case they did not develop gliomas, demonstrating that they had acquired a long-term resistance to the tumor cells, regardless of the presence of the exogenous hHER 2 receptor. Control mice $(n=5)$ transplanted with the same cells died, as expected, within 50 days (Fig. 3d).

\section{R-115 elicits production of antibodies and the infiltration of CD4- and CD8-positive cells in the tumor}

To provide direct evidence that R-115 elicits a tumorspecific immune response, we transplanted 14 additional mice with $\mathrm{mHGG}^{\text {pdgf }}$-hHER2 cells. After 21 days, six mice were injected with R-115 and 5 with R-LM113 $\left(2 \times 10^{6}\right.$ $\mathrm{PFU} / \mathrm{mouse}$ ). After further 20 days, we took the blood from the retro-orbital sinus to check whether the mice had

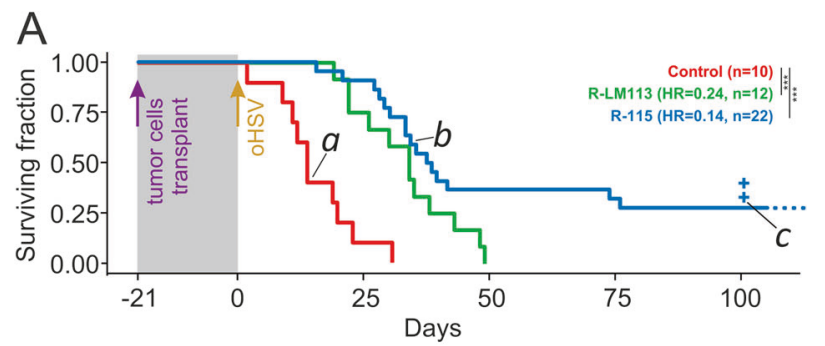

B
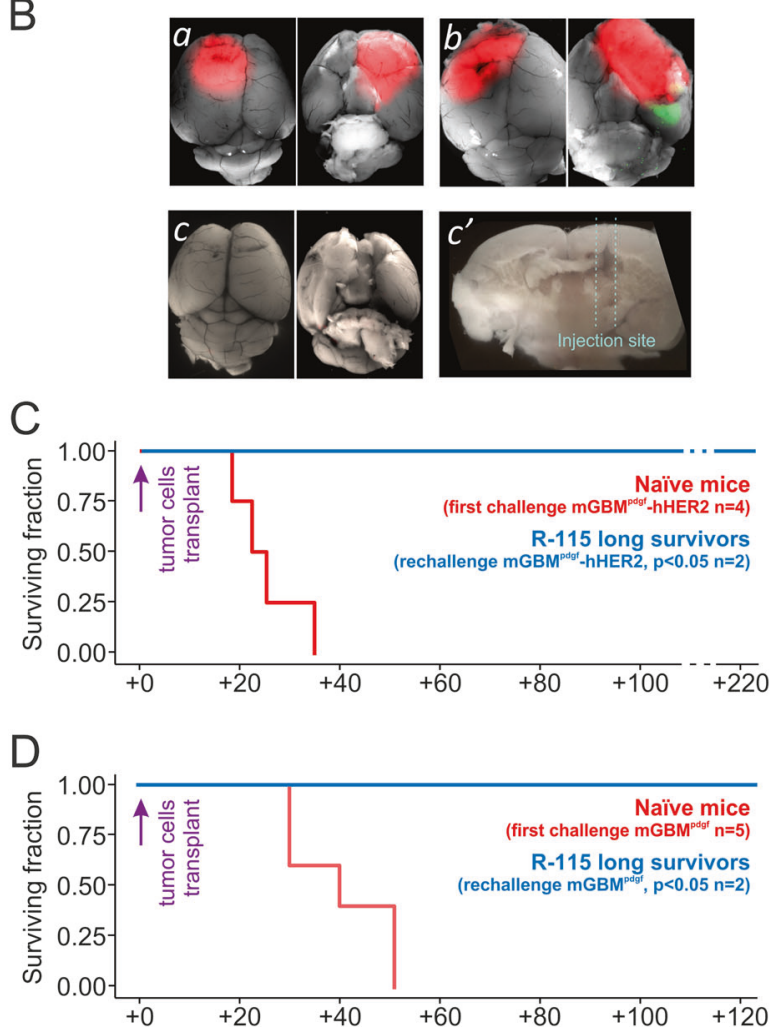

Fig. 3 a Kaplan Meyer survival curves of mice transplanted with $\mathrm{mHGG}^{\text {pdgf }}$ hHER 2 and treated after 21 days with R LM113 (green line), R 115 (blue line) and gamma irradiated R LM113 (control; red line). HR are indicated for the indicated arms compared to the control arm. *** Rank test $p$ values $<0.0001$. b Representative dorsal and ventral images of brains from mice of the control arm (a), the R 115 arm (b) and a long surviving mouse from R 115 arm, found to be tumor free (c). $c^{\prime}$ : coronal section of the brain of panel in $\mathrm{c}$ at the level of injection site. In all micrographs, the red channel shows the DsRed fluorescent reporter expressed by $\mathrm{mHGG}^{\text {pdgf }} \mathrm{hHER} 2$ cells, the green channel shows the viral reporter EGFP. c, d Kaplan Meyer curves of the long surviving mice from $\mathrm{R} 115$ arm (blue line) rechallenged by a second transplantation of $\mathrm{mHGG}^{\text {pdgf }} \mathrm{hHER} 2$ (c) or by a transplantation of the parental cells $\mathrm{mHGG}^{\text {pdgf }}$ lacking hHER2 receptor $(\mathbf{d})$ in the contralateral hemisphere, and control naïve mice transplanted with the same cells (red line)

developed antibodies targeting $\mathrm{mHGG}^{\text {pdgf }}$-hHER2 antigens. Blood was also drawn from two long-surviving mice from the R-115 arm of a previous experiment, from two nontransplanted mice (naïve), and from three mice transplanted with $\mathrm{mHGG}^{\text {pdgf }}$-hHER 2 cells and not treated with the virus. The plasma samples were assessed for the presence of 
A

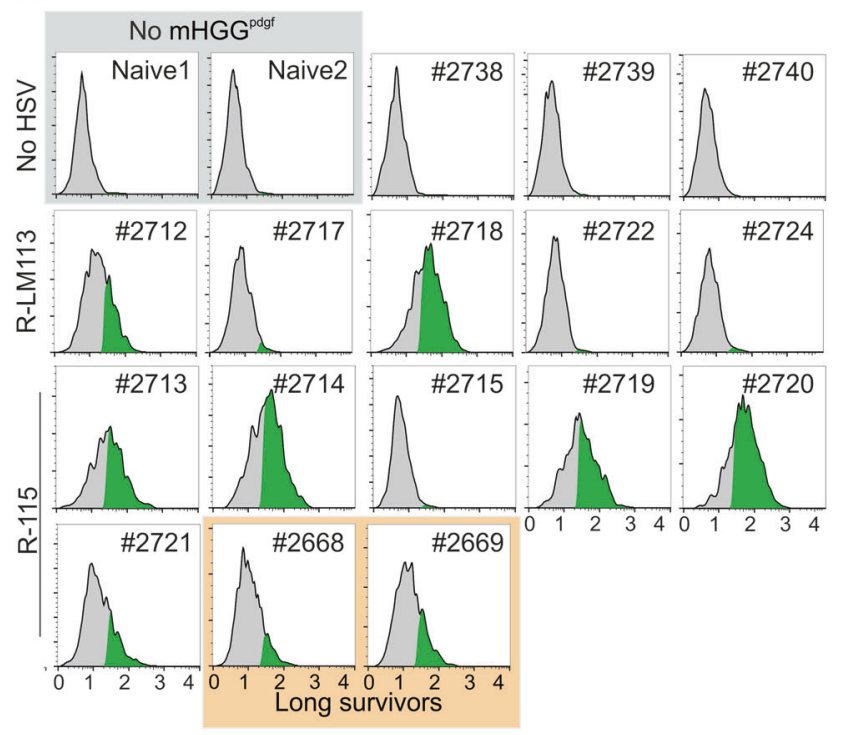

B
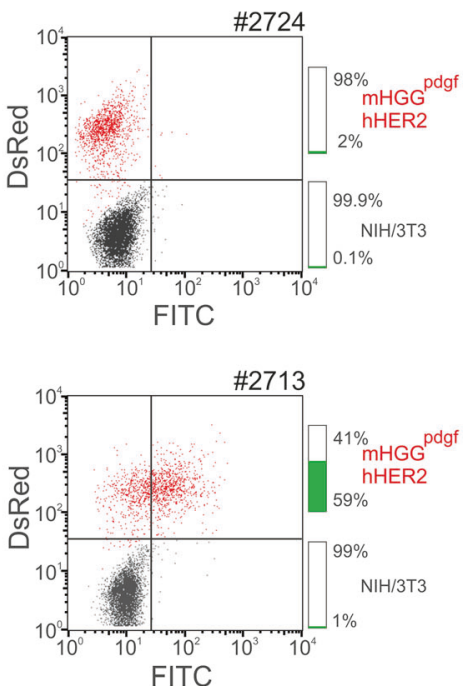

C

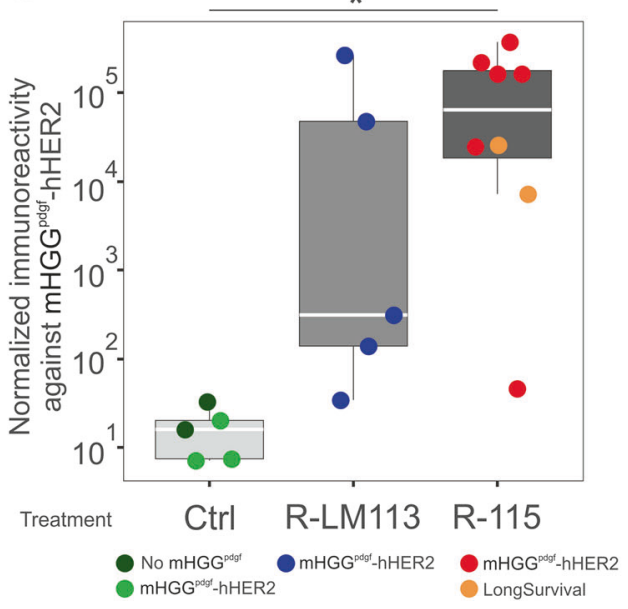

D

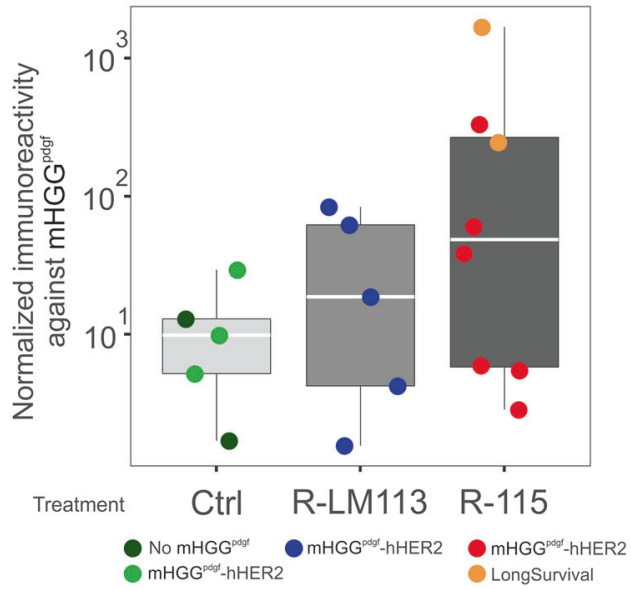

containing both $\mathrm{mHGG}^{\text {pdgf }}$ hHER2 (labeled with DsRed) and unla beled NIH/3T3 as negative control. c Ratio between (specifically) labeled $\mathrm{mHGG}^{\text {pdgf }} \mathrm{hHER} 2$ cells and the (unspecifically) labeled $\mathrm{NIH} / 3 \mathrm{~T} 3$, each normalized to the size of the respective population, calculated for all the plasma samples from control, R LM113, and R 115 arm (Anova $p<0.05$ ), graphed as boxplot. d The same assay was repeated using the parental $\mathrm{mHGG}^{\text {pdgf }}$ cells instead mHGG $^{\text {pdgf }}$ hHER2

contrast, immunoreactivity was clearly detectable in the plasma of two out of five animals from the R-LM113 group, and in five out of six animals from the R-115 group. Immunoreactivity was also detected in the plasma of both long-surviving mice. To evaluate the specificity of immunoreactivity of plasma samples, we took advantage of the internal negative control, which allowed to discriminate between specific and unspecific FITC signal. To do so, we normalized the fraction of $\mathrm{mHGG}^{\text {pdgf }}$-hHER 2 cells above a fixed FITC threshold to the fraction of NIH/3T3 cells above the same FITC threshold (i.e. unspecific signal; Fig. 4b). of mice receiving tumor cells but no virus injection. In 
This analysis performed on all animals allowed to test by one way Anova followed by a TukeyHSD post-hoc test the levels of immunoreactivity in the three groups. The analysis confirmed that there was a significant difference (Anova $p<0.05$ ) and the difference was between R-115 and the control group (Fig. 4c). Next, we carried out the same assay with the parental hHER2-negative $\mathrm{mHGG}^{\text {pdgf }}$ cells. The reactivity was much lower than that against mHGG $^{\text {pdgf }}$-hHER2, suggesting that the immune response elicited by oHSV infection was mainly targeting the xenogeneic hHER2 receptor. However, three plasma samples exhibited a higher reactivity: they belonged to the two longsurvivor mice from the R-115 arm of the first experiment, and to one of the mice that had received R-115 (Fig. 4d).

To further characterize the immune response likely boosted by IL-12 expression, we determined the isotypes of the immunoglobulins targeting glioma cells. Plasma samples drawn from mice belonging to the R-115 arm were incubated with $\mathrm{mHGG}^{\text {pdgf }}$-hHER2 cells, and afterward with FITC-conjugated anti-mouse isotype-specific secondary antibodies. While only one sample was found positive for IgG1 antibodies subclass, all of them resulted positive for at least one of the two IgG2 subtypes (Supplementary figure 3 ), typical, in the mouse, of cytotoxic response mediated by T-helper type 1 (TH1) [41].

IL-12 is known to activate T-cell response [42]. An increase in the number of T-lymphocytes a few days after oHSVs armed with mIL-12 was reported [43]. We analyzed the brains of 11 mice treated with R-LM113 or R-115 for 22 days after virus administration. The brains were analyzed for the presence of CD4- and CD8-positive cells by immunostaining. While the overall number of CD4- and CD8-positive cells did not significantly differ between animals treated with R-LM113 or with R-115, we observed a striking difference in their intratumoral distribution, depending on the injected oHSV. Thus, CD4- and CD8positive cells accumulated at the edge of the tumors treated with R-LM113, while they deeply infiltrated the tumor masses in the animals treated with the mIL-12 expressing R-115 (Fig. 5a-d). A quantification of the distances of CD4and CD8-positive cells inside the tumor masses from the nearest edge of the tumor was performed on five independent tumors for each treatment (Fig. 5e, f). $T$-test confirmed a significant difference between R-LM113 and R-115 groups for both CD4 and CD8 cells tumor localization $\left(p<10^{12}\right)$, arguing that the mIL-12 armed oHSV strongly promoted CD4- and CD8-positive infiltration of the tumor masses that, otherwise, tend to exclude lymphocytes.

To investigate whether in our experimental conditions the mIL-12 expression was inducing a similar path to that reported by other authors [25], hence suggesting a common mechanism, we assayed the expression of interferon- $\gamma$ (IFN$\gamma$ ) in a subset of samples treated with R-115 and R-LM113.
The immunohistochemical analysis showed that IFN- $\gamma$ expressing cells were present at a density greater than 5 cells $/ \mathrm{mm}^{2}$ in 3 out of 4 animals treated with R-115 and only in 1 out of 4 in animals treated with R-LM113 (Supplementary figure 4). This suggests that, analogously to what already reported in other systems, mIL-12 may act by enhancing the expression of IFN- $\gamma$.

\section{Discussion}

We report that more than one fourth of mice bearing a highly invasive orthotropic high-grade glioma (mHGG ${ }^{\text {pdgf }}$ ) at advanced stage, treated with a single injection of R-115, a hHER2-retargeted, fully virulent oHSV, armed with mIL12 , underwent permanent and complete remission and exhibited resistance to a distant re-challenge with the same tumor cells, as well as to a re-challenge with the parental $\mathrm{mHGG}^{\text {pdgf }}$ tumor, lacking hHER2 expression. To our knowledge, this is the first description of a complete tumor eradication achieved in this model of HGG. Even more importantly, the observation that resistance is extended to parental mHGGpdgf population lacking hHER2 indicates that the R-115 treatment, by stimulating an immune response, has good chances to be effective also against tumor that display heterogeneity in hHER2 expression.

The $\mathrm{mHGG}^{\text {pdgf }}$ model developed in this and previous studies [35] exhibits an immunosuppressive gene expression profile, similar to that shown by embryonically PDGFinduced gliomas [44] and that of human glioblastomas. Like human glioblastomas, it is rather resistant to a number of treatments, including chemotherapy and experimental gene therapy [45], and it invariably leads to animal death. In our experience, all the different treatments tested so far (temozolomide administration, peptide immunotherapy, oHSVs) on $\mathrm{mHGG}^{\text {pdgf }}$ harboring mice led, at best, to an improvement in the median survival time [34, 35, 45]. So far, one of the most effective treatments was that with the fully virulent retargeted oHSV (R-LM113) [34] i.e. the unarmed parent of R-115 [37]. In the present work, as few as $2 \times 10^{6} \mathrm{PFU}$ of R-115 was administered in a single injection session in animals harboring already established tumors. Noteworthy, the timing for treatment was selected to be shortly before the first animals exhibited disease symptoms, as inferred from previously determined survival curves for $\mathrm{mHGG}^{\text {pdgf }}-\mathrm{hHER} 2$. Furthermore, our data show that a 50fold increase in the amount of administered virus did not lead to higher efficacy, implying that, at least with this administration protocol, as few as $2 \times 10^{6} \mathrm{PFU}$ of fully virulent mIL-12 expressing virus is already a saturating amount. Not all treated mice responded uniformly. While some mice fully recovered, others showed only an increased survival time. Heterogeneity in the response to treatment 
A

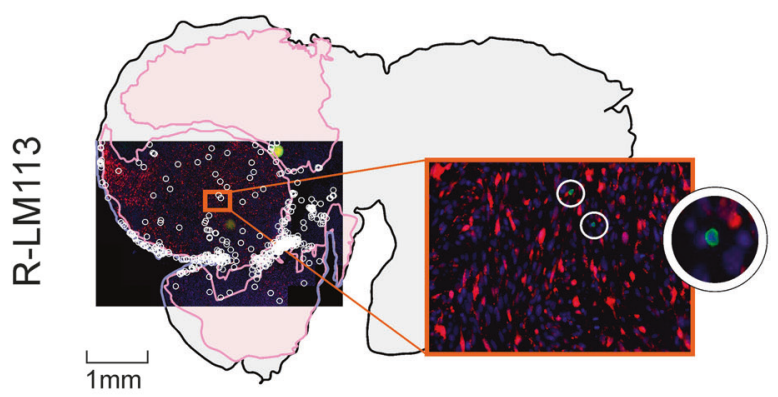

C

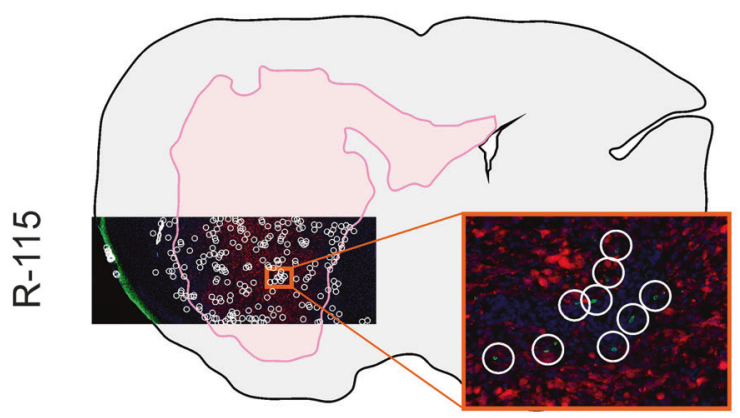

$E$

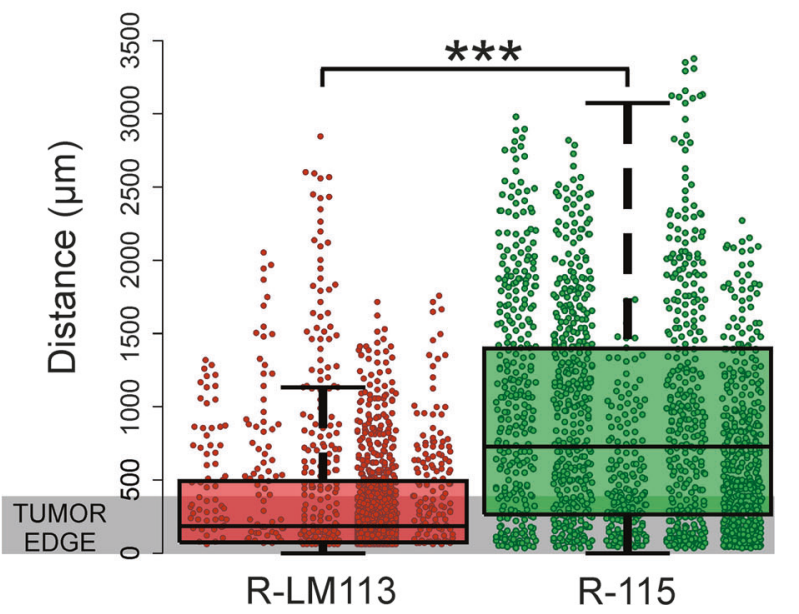

Fig. 5 Brain sections of mice transplanted with $\mathrm{mHGG}^{\text {pdgf }}$ hHER2 cells and treated with R LM113 (a, b) or with R 115 (c, d) were immunostained for CD4 (a, c) or CD8 (b, d). Positive cells (green) were encircled in white as shown in the inserts. Tumors are repre sented as pink areas. (e, f) The distance from the nearest edge of the

may have different concurring reasons. Among the likeliest are the difference in tumor size at the time of the treatment and the stochastic nature of the immune response. From previous studies, we know that transplanted gliomas grow roughly exponentially by doubling their size in 24 days [46]. Therefore, although their survival time is relatively homogeneous ( $38 \pm 8$ days in the control group), the tumor size at any given time may vary substantially (from 4 to 8 doublings i.e. up to 250 times). These differences are likely
B CD8

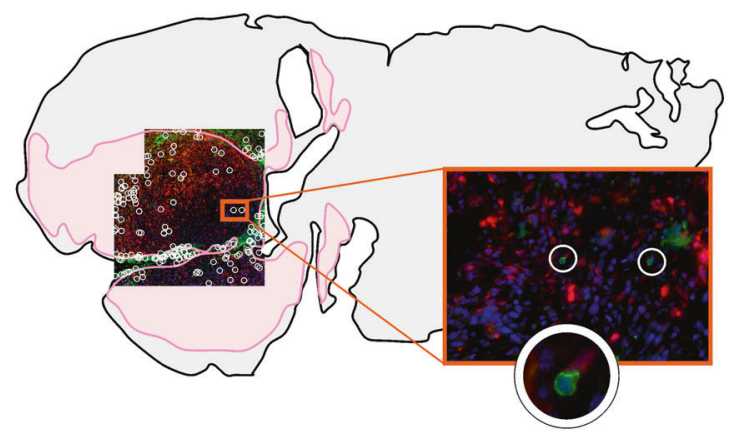

D

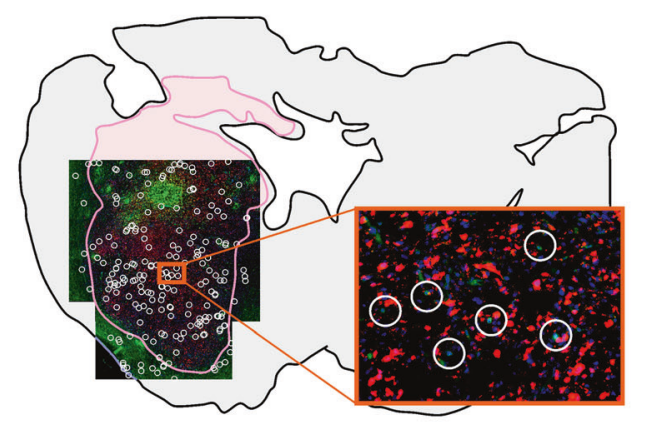

$\mathrm{F}$

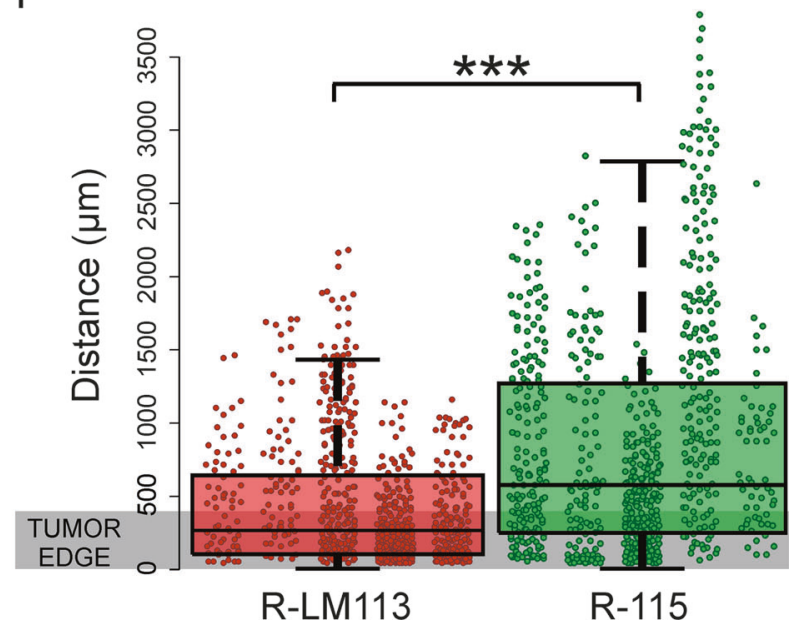

tumor mass of each CD4 positive cell (e) or CD8 positive cell (f) inside the tumor was measured in sections of 10 independent ani mals treated with R LM113 or R 115. The results are depicted as bee swarm plots and cumulative box plots ( $t$ test $p<10^{-12}$ )

affecting the percentage of infected cells and, possibly, the intensity of the immune response, which, per se, has been early recognized highly variable even in syngeneic populations subjected to the same stimulus [47]. This concept that has been later corroborated by different studies [48]. The variability of the immune response is well illustrated by the observation that only a subset of R-115-treated mice developed a significant immunoreactivity against the nonhHER2 expressing parental population. 
Our observations show that the mIL-12 expressing hHER2 retargeted R-115 enhanced the production of antibodies targeting the transplanted glioma cells. The immunoreactivity was mostly directed to the exogenous human receptor hHER2, expressed by $\mathrm{mHGG}^{\text {pdgf }}$-hHER2. A subset of animals (about 1/3, among which the long survivors) showed immunoreactivity also against the parental $\mathrm{mHGG}^{\text {pdgf }}$ cells, lacking hHER2. Antibodies targeting tumor cells mainly belonged to the IgG2 isotype rather than the IgG1, a feature expected to be observed during a cytotoxic Th1-mediated immune response [41]. This observation fits with the enhancing of the secretion of IFN$\gamma$, observed in tumors treated by virus carrying mIL-12 25 and Supplementary Fig. 4.

Our analysis on brain sections did not highlight differences in the total amount of CD4- and CD8-positive T-lymphocytes depending on treatment. However, a striking difference was evident in the distribution of these cells 20 days after virus injection. In mice treated with R-LM113, CD4- and CD8-positive lymphocytes appeared confined at the tumor edges, as observed in cold (i.e. excluded) tumors [49]. In contrast, CD4 and CD8 T-lymphocytes deeply infiltrated the tumor masses in mice treated with R-115 arguing that mIL-12 influenced the immune cell landscape within the immunosuppressive tumor microenvironment, making tumor mass more permissive to cytotoxic lymphocytes infiltration. Data observed are consistent with the observation reported by Cheema et al. that depletion of T-lymphocytes abolishes the ability of IL-12 armed oHSVs in counteracting tumors [25].

The overall median survival time of mice treated with R-115 was doubled in comparison to that of the mocktreated animals, although it was not significantly different from that of the animals treated with the non-armed version of the oHSV (R-LM113). Current findings differ from the reported efficacy study on mIL-12-armed versus non-armed versions of mutated/attenuated oHSVs, which carry the deletion of the $\gamma_{1} 34.5$ virulence gene [25, 43]. The main difference between our and the former results lies in the higher efficacy of R-LM113 on the overall survival time: indeed, unlike mutated/attenuated oHSVs, fully virulent unarmed R-LM113 was capable of doubling the median survival time even when injected in large neoplastic masses.

It is likely that if the protocol of R-115 administration were similar to that employed in earlier studies, which consisted of repeated sessions of injections or earlier treatments [25], the R-115 efficacy would be much higher. Recently, high percentages of experimental glioma eradication in immunocompetent mice were achieved with a mIL-12 expressing attenuated oHSV [50]. Of note, that extent of eradication was only achieved when the mIL-12 expressing oHSV was employed in simultaneous combination with two immune checkpoint inhibitors (anti-CTLA-
4 and anti-PD1 antibodies); no eradication was achieved with the mIL-12 armed o-HSV alone or the two checkpoint inhibitors in the absence of the o-HSV.

R-115 was recently recognized effective against a model of HER2-Lewis lung carcinoma [51]. This study now provides a proof of concept of the benefits of a retargeted, fully virulent, oHSVs over mutated/attenuated oHSVs to counteract HGGs by overexpressing mIL-12 and suggests they are candidates worth to be explored for oHSV-based glioblastoma treatment, most likely in combination with immune checkpoint inhibitors.

\section{Materials and methods}

\section{Animal procedures}

Mice were handled in agreement with the guidelines conforming to current Italian regulations for the protection of animals used for scientific purposes (D.lvo 27/01/1992, no. 116). Procedures were approved by the Ethical Committee for Animal Experimentation of the National Institute of Cancer Research and by the Italian Ministry of Health. The experiments were performed with the BALB/c mouse strain using animals between 3 and 6 months of either sex.

Tumors were implanted by injecting a suspension of $2 \times$ $10^{4}$ cells in adult mouse brains using a Hamilton syringe (Bregma coordinates: anterior posterior, $1.0 \mathrm{~mm}$ anterior; lateral, and $2.5 \mathrm{~mm}$ below the skull surface). Twenty-one days after tumor implantation, $5 \mu \mathrm{l}$ oHSV preparation, containing $2 \times 10^{6}$ or $10^{8}$ PFU of either R-115 or R-LM113 or gamma-irradiated R-LM113 were injected at the same stereotaxic coordinates. Animals were monitored daily and were killed at first signs of neurological symptoms or at the predetermined time point. Their brains were photographed by fluorescence stereomicroscope (Wetzlar, Germany).

Survival curves were determined using Kaplan Meier survival between groups and compared by the log-rank test. The minimum sample size was preliminary established based on log-rank power analysis, assuming an effect size $\mathrm{HR} \leq 0.33$ and a power of $1 \quad \beta \geq 0.8$.

Mice were randomly assigned to the different experimental arms by assigning them a unique ID and using Microsoft Excel pseudorandom generator to sort them. The animals that did not survive intracranial injection procedure and died within 3 days from virus injection were excluded from the experiment.

Up to $0.3 \mathrm{ml}$ of blood was withdrawn 20 days after treatment with oHSV. In addition, we took blood from longsurviving mice, 4 days after the transplantation of $\mathrm{mHGG}^{\text {pdgf }}$-hHER2 in the contralateral hemisphere. Heparinized capillaries were used for retro-orbital bleeding procedure. Samples were incubated for $6 \mathrm{~h}$ at $60^{\circ} \mathrm{C}$ with 
heparin. Cells were removed from serum by centrifugation (10 min at $2000 g$ with refrigerated centrifuge).

\section{Cell cultures and infection}

PDGF-B-induced brain tumors expressing DsRed fluorescent reporter were obtained as previously described [35]. Cells derived from primary tumors were maintained onto plates coated with Matrigel matrix (1:200; BD Biosciences, Franklin Lakes, NJ) in Dulbecco's Modified Eagle Medium (DMEM)/F12 (Gibco-Life Technologies, Carlsbad, CA, USA) added with B27 supplement (Gibco-Life Technologies, Carlsbad, CA, USA), recombinant human FGF2 (10 $\mathrm{ng} / \mathrm{ml}$; PeproTech, Rocky Hill, USA) and recombinant human EGF (10 ng/ml; PeproTech, Rocky Hill, USA). $\mathrm{mHGG}^{\text {pdgf }}$ cells were transduced with RAVI-hHER2 retroviral vectors and sorted by FACS based on the expression of the receptor.

Human glioma-initiating cells were produced as described elsewhere [39] and maintained onto plates coated with Matrigel matrix (1:200; BD Biosciences, Franklin Lakes, NJ) in DMEM/F12 and Neurobasal (Gibco-Life Technologies, Carlsbad, CA, USA), supplemented with B27 supplement (Gibco-Life Technologies, Carlsbad, CA, USA), L-glutamine ( $2 \mathrm{mM}$, Euroclone, Pero (MI), Italy) penicillin-streptomycin (Euroclone, Pero (MI), Italy), recombinant human basic FGF (10 ng/ml; Peprotech, Rocky Hill, USA), and recombinant human EGF $(20 \mathrm{ng} / \mathrm{ml}$; Peprotech, Rocky Hill, USA).

The construction and production of the recombinant oHSVs R-LM113 and R-115, retargeted to hHER2, were described elsewhere [37, 52]). Three technical replicates of cells were infected with R-115 or R-LM113, at the indicated MOI estimated on the basis of titer determined in SK-OV-3 cells. The efficiency of infection was monitored under inverted microscope (EVOS FL Cell Imaging System, ThermoFisher Scientific, Waltham, MA, USA) by means of enhanced green fluorescent protein (EGFP) expression for both viruses. The percentage of infected cells was evaluated measuring the fluorescence intensity of cells by flow cytometry (CyAn ADP, Beckman Coulter, Indianapolis, IN, USA).

mIL-12 was quantified from the supernatants of three independent technical replicates of $\mathrm{mHGG}^{\text {pdgf }}$-hHER2 cells infected at $0.1,0.3$ or 1 PFU/cell with R-LM113 or R-115, using the Mouse IL-12 (p70) ELISA Plate kit (ThermoFisher Scientific, Waltham, MA, USA).

\section{Immunostaining and flow cytometry}

For flow cytometry and cell sorting, $\mathrm{mHGG}^{\text {pdgf }}$-hHER2 cells were stained in suspension with mouse monoclonal antibody against hHER2 $\left(1 \mu \mathrm{g} / 10^{6}\right.$ cells; Santa Cruz
Biotechnology, Santa Cruz, CA, USA, \#Sc-08). Binding of primary antibody was revealed with secondary anti-mouse $\mathrm{Cy}^{\mathrm{TM}}$ 2-conjugated, (1:50; Jackson Immunoresearch, Milano, Italy, \#115-485-003).

To detect antibodies in murine plasma, tumor cells and $\mathrm{NIH} / 3 \mathrm{~T} 3$ cells (in ratio $1: 1.5$ ) were incubated for $1 \mathrm{~h}$ at $4{ }^{\circ} \mathrm{C}$ with plasma diluted in saline solution (1:5). After washing in PBS, cells were incubated for $30 \mathrm{~min}$ with secondary anti-mouse antibodies (anti IgG: $\mathrm{Cy}^{\mathrm{TM}_{2}}$ conjugated, Jackson Immunoresearch, Milano, Italy; anti IgG1, anti IgG2a, anti-IgG2b: Southern Biotech, Birmingham, AL USA, \#1071-02, \#1081-02, and 1091-02) and analyzed by flow cytometry (CyAn ADP, Beckman Coulter, Indianapolis, IN, USA). Positive control consisted of mouse monoclonal antibody against hHER2 and secondary anti-mouse $\mathrm{Cy}^{\mathrm{TM}}$ 2-conjugated. The proportion of DsRed-positive mHGG $^{\text {pdgf }}$-hHER2 cells above a threshold on the FITCfluorescence axis among the cells were normalized to the mean of the proportion of cells above the same threshold among the DsRed-negative in all samples.

To detect apoptotic/necrotic population, three different hGic cell cultures 6 days after R-115 infection were analyzed by using the GFP-CERTIFIED ${ }^{\circledR}$ Apoptosis/Necrosis Detection Kit (Enzo Life Sciences, Farmingdale, NY, USA). Cells treated for $4 \mathrm{~h}$ with staurosporine included in the kit were used as positive control.

FlowJo software v10.0.7 was used for flow cytometry data analyses.

For histological analysis, brains were fixed with $4 \%$ paraformaldehyde, cryoprotected in $20 \%$ sucrose and sectioned with a Leica CM3050 S cryostat. Immunostainings on brain sections or cultured cells were performed using mouse monoclonal antibody against CD4 (1:500, BD Pharmingen, San Diego, CA, USA, \#550280) or CD8 (1:200, Novus Biological, Littleton, USA, \#B173835). Binding of primary antibody was revealed with secondary anti-rat Alexa 488-conjugated (1:500; Jackson Immunoresearch, Milano, Italy. \#112-545-003). The shapes of the sections of tumor masses and positions of CD4 and CD8 were acquired by epifluorescence microscope (Axio Imager. M2, Zeiss, Oberkochen, Germany) by using AxioVision Rel. 4.8 (Zeiss, Oberkochen, Germany) and Slide Explorer2 plug-in of Micromanager [53]. A set scripts for R 3.4.0 [54] developed in house (available on request) were used to produce the overlay between pictures and acquired positions of lymphocytes and to calculate their distances from the tumor edges.

Immunohistochemical stainings on brain sections were performed using mouse IFN- $\gamma$ antibody (1:500, Biolegend, San Diego, CA, USA, \#505806). Binding of primary antibody was revealed with secondary anti-rat biotine-conjugated antibody (1:500, Sigma-Aldrich Saint Louis, USA, \# B7139) and then with HRP-conjugated streptavidin 
(1:250, R\&D Biosystem, Minneapolis, USA, \#890803) and revealed with AEC (3-amino-9-ethylcarbazole). Cells nuclei were controstained with hematoxylin. Images of tumor areas were acquired with Eclipse 80i microscope (Nikon Corporation, Tokyo, Japan). The images obtained with AEC dye were processed using Photoshop CC2018 (Adobe Systems; Tokyo, Japan) to reconstruct the image of tumor areas and then were analyzed with Fiji software [55].

\section{RNA sequencing}

For whole-exome sequencing, at least $0.01 \mu \mathrm{g}$ RNA derived from three ex-vivo primary tumor samples, sorted by FACS for DsRed reporter and harvested in Trizol, was sent to BGI genomics (BGI, Shenzhen, China) and sequenced on BGISEQ-500 RS generating 50 base-pair single-end reads. The high-quality clean tags were mapped to reference genome (mm10) using STAR [56]. To quantify the gene expression level, RSEM analysis was carried out [57], acquiring read count of each gene of each sample, based on the mapping results. Normalization and data trimming were performed by edgeR [58]. Raw and processed data are available on GEO Dataset (accession number GSE109614).

\section{Statistical methods}

Sample sizes for each experiment are indicated in the results or in the material and methods sections. Statistical analyses were performed with two-sided $t$-test when between two conditions, one-way ANOVA followed by Tukey HSD post-hoc test when between more conditions. Survival analyses were performed with log-rank test. Error bars represent standard deviations. Numerical values are reported as mean \pm standard deviation.

Acknowledgments This work was supported by European Research Council (ERC) advanced grant number 340060 to GCF and PM; by Compagnia di San Paolo, Turin, Italy (grant no 2015.9834) "Terapie innovative per il glioblastoma" to PM; by RFO (University of Bologna) to LM and EA. We would like to thank Dr. Antonio Daga for providing human glioma initiating cells.

\section{Compliance with ethical standards}

Conflict of interest GCF owns shares in Nouscom. GCF and LM receive equity payments from Amgen. The funding sponsors had no role in the design of the study; in the collection, analyses, or inter pretation of data; and in the writing of the manuscript. The other authors declare that they have no conflict of interest.

Publisher's note: Springer Nature remains neutral with regard to jurisdictional claims in published maps and institutional affiliations.

\section{References}

1. Hunter WD, Martuza RL, Feigenbaum F, Todo T, Mineta T, Yazaki T, et al. Attenuated, replication competent herpes simplex virus type 1 mutant G207: safety evaluation of intracerebral injection in nonhuman primates. J Virol. 1999;73:6319 26.

2. Martuza RL, Malick A, Markert JM, Ruffner KL, Coen DM. Experimental therapy of human glioma by means of a genetically engineered virus mutant. Science. 1991;252:854 6.

3. Mineta T, Rabkin SD, Yazaki T, Hunter WD, Martuza RL. Attenuated multi mutated herpes simplex virus 1 for the treatment of malignant gliomas. Nat Med. 1995;1:938 43.

4. Campadelli Fiume G, Petrovic B, Leoni V, Gianni T, Avitabile E, Casiraghi $\mathrm{C}$, et al. Retargeting strategies for oncolytic herpes simplex viruses. Viruses. 2016;8:63.

5. Campadelli Fiume G, De Giovanni C, Gatta V, Nanni P, Lollini PL, Menotti L. Rethinking herpes simplex virus: the way to oncolytic agents. Rev Med Virol. 2011;21:213 26.

6. Delman KA, Bennett JJ, Zager JS, Burt BM, McAuliffe PF, Petrowsky $\mathrm{H}$, et al. Effects of preexisting immunity on the response to herpes simplex based oncolytic viral therapy. Hum Gene Ther. 2000;11:2465 72 .

7. Lambright ES, Kang EH, Force S, Lanuti M, Caparrelli D, Kaiser LR, et al. Effect of preexisting anti herpes immunity on the effi cacy of herpes simplex viral therapy in a murine intraperitoneal tumor model. Mol Ther. 2000;2:387 93.

8. Coffin RS. From virotherapy to oncolytic immunotherapy: where are we now? Curr Opin Virol. 2015;13:93 100.

9. Kemeny N, Brown K, Covey A, Kim T, Bhargava A, Brody L, et al. Phase I, open label, dose escalating study of a genetically engineered herpes simplex virus, NV1020, in subjects with metastatic colorectal carcinoma to the liver. Hum Gene Ther. 2006;17:1214 24.

10. Kimata H, Imai $T$, Kikumori $T$, Teshigahara $O$, Nagasaka $T$, Goshima F, et al. Pilot study of oncolytic viral therapy using mutant herpes simplex virus (HF10) against recurrent metastatic breast cancer. Ann Surg Oncol. 2006;13:1078 84.

11. Nakao A, Kasuya H, Sahin TT, Nomura N, Kanzaki A, Misawa $\mathrm{M}$, et al. A phase I dose escalation clinical trial of intraoperative direct intratumoral injection of HF10 oncolytic virus in non resectable patients with advanced pancreatic cancer. Cancer Gene Ther. 2011;18:167 75 .

12. Liu BL, Robinson M, Han ZQ, Branston RH, English C, Reay P, et al. ICP34.5 deleted herpes simplex virus with enhanced onco lytic, immune stimulating, and anti tumour properties. Gene Ther. 2003;10:292 303 .

13. Andtbacka RH, Kaufman HL, Collichio F, Amatruda T, Senzer N, Chesney J, et al. Talimogene laherparepvec improves durable response rate in patients with advanced melanoma. J Clin Oncol. 2015;33:2780 8

14. Markert JM, Medlock MD, Rabkin SD, Gillespie GY, Todo T, Hunter WD, et al. Conditionally replicating herpes simplex virus mutant, G207 for the treatment of malignant glioma: results of a phase I trial. Gene Ther. 2000;7:867 74.

15. Kambara H, Okano H, Chiocca EA, Saeki Y. An oncolytic HSV 1 mutant expressing ICP34.5 under control of a nestin promoter increases survival of animals even when symptomatic from a brain tumor. Cancer Res. 2005;65:2832 9.

16. Louis DNO H, Wiestler OD, Cavenee WK. World Health Orga nization Histological Classification of Tumours of the Central Nervous System. Revise 4th edn. Lyon: IARC Press; 2016.

17. Stupp R, Hegi ME, Mason WP, van den Bent MJ, Taphoorn MJ, Janzer RC, et al. Effects of radiotherapy with concomitant and adjuvant temozolomide versus radiotherapy alone on survival in glioblastoma in a randomised phase III study: 5 year analysis of the EORTC NCIC trial. Lancet Oncol. 2009;10:459 66.

18. Louveau A, Harris TH, Kipnis J. Revisiting the mechanisms of cns immune privilege. Trends Immunol. 2015;36:569 77.

19. Korn T, Kallies A. T cell responses in the central nervous system. Nat Rev Immunol. 2017;17:179 94. 
20. Toda M, Martuza RL, Kojima H, Rabkin SD. In situ cancer vaccination: an IL 12 defective vector/replication competent herpes simplex virus combination induces local and systemic antitumor activity. J Immunol. 1998;160:4457 64.

21. Veinalde R, Grossardt C, Hartmann L, Bourgeois Daigneault MC, Bell JC, Jager D, et al. Oncolytic measles virus encoding interleukin 12 mediates potent antitumor effects through $\mathrm{T}$ cell activation. Oncoimmunology. 2017;6:e1285992.

22. Parker JN, Gillespie GY, Love CE, Randall S, Whitley RJ, Markert JM. Engineered herpes simplex virus expressing IL 12 in the treatment of experimental murine brain tumors. Proc Natl Acad Sci USA. 2000;97:2208 13.

23. Thomas ED, Meza Perez S, Bevis KS, Randall TD, Gillespie GY, Langford C, et al. IL 12 Expressing oncolytic herpes simplex virus promotes anti tumor activity and immunologic control of metastatic ovarian cancer in mice. J Ovarian Res. 2016;9:70.

24. Cody JJ, Scaturro P, Cantor AB, Yancey Gillespie G, Parker JN, Markert JM. Preclinical evaluation of oncolytic deltagamma(1) 34.5 herpes simplex virus expressing interleukin 12 for therapy of breast cancer brain metastases. Int $\mathrm{J}$ Breast Cancer. 2012;2012:628697.

25. Cheema TA, Wakimoto H, Fecci PE, Ning J, Kuroda T, Jeyaretna DS, et al. Multifaceted oncolytic virus therapy for glioblastoma in an immunocompetent cancer stem cell model. Proc Natl Acad Sci USA. 2013;110:12006 11.

26. Patel DM, Foreman PM, Nabors LB, Riley KO, Gillespie GY, Markert JM. Design of a phase I clinical trial to evaluate M032, a genetically engineered HSV 1 expressing IL 12, in patients with recurrent/progressive glioblastoma multiforme, anaplastic astro cytoma, or gliosarcoma. Hum Gene Ther Clin Dev. 2016;27:69 78.

27. Duhem Tonnelle V, Bieche I, Vacher S, Loyens A, Maurage CA, Collier $\mathrm{F}$, et al. Differential distribution of erbB receptors in human glioblastoma multiforme: expression of erbB3 in CD133 positive putative cancer stem cells. J Neuropathol Exp Neurol. 2010;69:606 22.

28. Mineo JF, Bordron A, Baroncini M, Maurage CA, Ramirez C, Siminski RM, et al. Low HER2 expressing glioblastomas are more often secondary to anaplastic transformation of low grade glioma. J Neurooncol. 2007;85:281 7.

29. Nabika S, Kiya K, Satoh H, Mizoue T, Kondo H, Katagiri M, et al. Prognostic significance of expression patterns of EGFR family, p21 and p27 in high grade astrocytoma. Hiroshima J Med Sci. 2010;59:65 70 .

30. Gulati S, Ytterhus B, Granli US, Gulati M, Lydersen S, Torp SH. Overexpression of cerbB2 is a negative prognostic factor in anaplastic astrocytomas. Diagn Pathol. 2010;5:18.

31. Hiesiger EM, Hayes RL, Pierz DM, Budzilovich GN. Prognostic relevance of epidermal growth factor receptor (EGF R) and c neu/ erbB2 expression in glioblastomas (GBMs). J Neurooncol. 1993;16:93 104

32. Ahmed N, Salsman VS, Kew Y, Shaffer D, Powell S, Zhang YJ, et al. HER2 specific $\mathrm{T}$ cells target primary glioblastoma stem cells and induce regression of autologous experimental tumors. Clin Cancer Res. 2010;16:474 85.

33. Uhlen M, Fagerberg L, Hallstrom BM, Lindskog C, Oksvold P, Mardinoglu A, et al. Proteomics. Tissue based map of the human proteome. Science. 2015;347:1260419.

34. Gambini E, Reisoli E, Appolloni I, Gatta V, Campadelli Fiume G, Menotti L, et al. Replication competent herpes simplex virus retargeted to HER2 as therapy for high grade glioma. Mol Ther. 2012;20:994 1001.

35. Reisoli E, Gambini E, Appolloni I, Gatta V, Barilari M, Menotti L, et al. Efficacy of HER2 retargeted herpes simplex virus as therapy for high grade glioma in immunocompetent mice. Cancer Gene Ther. 2012;19:788 95.
36. Uchida H, Marzulli M, Nakano K, Goins WF, Chan J, Hong CS, et al. Effective treatment of an orthotopic xenograft model of human glioblastoma using an EGFR retargeted oncolytic herpes simplex virus. Mol Ther. 2013;21:561 9.

37. Menotti L, Avitabile E, Gatta V, Malatesta P, Petrovic B, Campadelli Fiume G. HSV as a platform for the generation of retargeted, armed, and reporter expressing oncolytic viruses. Viruses. 2018;10. https://doi.org/10.3390/v10070352.

38. Hausler SF, Montalban del Barrio I, Strohschein J, Chandran PA, Engel JB, Honig A, et al. Ectonucleotidases CD39 and CD73 on OvCA cells are potent adenosine generating enzymes responsible for adenosine receptor $2 \mathrm{~A}$ dependent suppression of $\mathrm{T}$ cell func tion and NK cell cytotoxicity. Cancer Immunol Immunother. 2011;60:1405 18

39. Banelli B, Carra E, Barbieri F, Wurth R, Parodi F, Pattarozzi A, et al. The histone demethylase KDM5A is a key factor for the resistance to temozolomide in glioblastoma. Cell Cycle. 2015;14:3418 29.

40. Guo H, Kaiser WJ, Mocarski ES. Manipulation of apoptosis and necroptosis signaling by herpesviruses. Med Microbiol Immunol. 2015;204:439 48

41. Mosmann TR, Coffman RL. Heterogeneity of cytokine secretion patterns and functions of helper $\mathrm{T}$ cells. Adv Immunol. 1989;46:111 47.

42. Trinchieri G. Interleukin 12 and the regulation of innate resistance and adaptive immunity. Nat Rev Immunol. 2003;3:133 46.

43. Hellums EK, Markert JM, Parker JN, He B, Perbal B, Roizman B, et al. Increased efficacy of an interleukin 12 secreting herpes simplex virus in a syngeneic intracranial murine glioma model. Neuro Oncol. 2005;7:213 24.

44. Appolloni I, Alessandrini F, Ceresa D, Marubbi D, Gambini E, Reverberi D, et al. Progression from low to high grade in a glioblastoma model reveals the pivotal role of immunoediting. Cancer Lett. 2018;442:213 21.

45. Favaro R, Appolloni I, Pellegatta S, Sanga AB, Pagella P, Gam bini $\mathrm{E}$, et al. Sox 2 is required to maintain cancer stem cells in a mouse model of high grade oligodendroglioma. Cancer Res. 2014;74:1833 44

46. Alessandrini F, Ceresa D, Appolloni I, Marubbi D, Malatesta P. Noninvasive monitoring of glioma growth in the mouse. J Cancer. 2016;7:1791 7.

47. Bystryn JC. Antibody response and tumor growth in syngeneic mice immunized to partially purified B16 melanoma associated antigens. J Immunol. 1978;120:96 101.

48. Pritchard CC, Hsu L, Delrow J, Nelson PS. Project normal: defining normal variance in mouse gene expression. Proc Natl Acad Sci USA. 2001;98:13266 71.

49. van der Woude LL, Gorris MAJ, Halilovic A, Figdor CG, de Vries IJM. Migrating into the tumor: a roadmap for $\mathrm{t}$ cells. Trends Cancer. 2017;3:797 808.

50. Saha D, Martuza RL, Rabkin SD. Macrophage polarization con tributes to glioblastoma eradication by combination immunovir otherapy and immune checkpoint blockade. Cancer Cell. 2017;32:253 267 e255.

51. Leoni V, Vannini A, Gatta V, Rambaldi J, Sanapo M, Barboni C, et al. A fully virulent retargeted oncolytic HSV armed with IL 12 elicits local immunity and vaccine therapy towards distant tumors. PLoS Pathog. 2018;14:e1007209.

52. Menotti L, Cerretani A, Hengel H, Campadelli Fiume G. Con struction of a fully retargeted herpes simplex virus 1 recombinant capable of entering cells solely via human epidermal growth factor receptor 2. J Virol. 2008;82:10153 61.

53. Edelstein A, Amodaj N, Hoover K, Vale R, Stuurman N Com puter control of microscopes using microManager. Curr Protoc Mol Biol. 2010; Chapter 14: Unit 14 20. https://doi.org/10.1016/j. canlet.2018.10.006. 
54. R Core Team. R: A language and environment for statistical com puting. Vienna: R Foundation for Statistical Computing; 2017.

55. Schindelin J, Arganda Carreras I, Frise E, Kaynig V, Longair M, Pietzsch T, et al. Fiji: an open source platform for biological image analysis. Nat Methods. 2012;9:676 82.

56. Dobin A, Gingeras TR. Mapping RNA seq reads with STAR. Curr Protoc Bioinforma. 2015;51:11 19. 1114
57. Li B, Dewey CN. RSEM: accurate transcript quantification from RNA Seq data with or without a reference genome. BMC Bioinforma. 2011;12:323.

58. Robinson MD, McCarthy DJ, Smyth GK. edgeR: a Bio conductor package for differential expression analysis of digital gene expression data. Bioinformatics. 2010;26: 13940. 